\title{
Low rates of exclusive breastfeeding are still evident in four South African provinces
}

\author{
Siziba LP, MSc, PhD Student, Jerling J, PhD, Director \\ Centre of Excellence for Nutrition, North-West University, Potchefstroom, South Africa \\ Hanekom SM, PhD, Director, School of Physiology, Nutrition and Consumer Sciences, \\ Centre of Excellence for Nutrition, North-West University, Potchefstroom, South Africa \\ Wentzel-Viljoen E, PhD, Extraordinary Professor of Nutrition \\ Centre of Excellence for Nutrition and Medical Research Council Research Unit for Hypertension and Cardiovascular Disease \\ Faculty of Health Sciences, North-West University, Potchefstroom, South Africa \\ Correspondence to: Linda Siziba, e-mail: sizibaleeprecious@gmail.com \\ Keywords: exclusive breastfeeding, South Africa, low rates, infant feeding practices
}

\section{Abstract}

Objectives: Breastfeeding is one of the primary strategies used to enhance infant nutrition and improving child survival worldwide. The intention of globally increasing the rate of exclusive breastfeeding (EBF) to at least $50 \%$ of infants in the first six months of life was stated in the 2014 International Conference on Nutrition Rome Declaration on Nutrition and the Post-2015 Development Agenda. This study aimed to explore the infant-feeding practices of mothers and caregivers of infants aged $\leq 6$ months in four provinces in South Africa.

Setting and subjects: This cross-sectional study was conducted in four provinces in South Africa. In total, 40 health facilities were randomly selected in the four provinces and visited, including metropolitan and non-metropolitan health facilities over the geographical area of the provinces. The sample size comprised mothers and/or caregivers of babies aged $\leq 6$ months.

Design: Fixed-format interviews were used in this cross-sectional study on 580 mothers and/or caregivers. The mothers completed 24-hour recall based on the Food and Agriculture Organization of the United Nations dietary diversity list, consisting of 12 different food groups, to assess dietary intake and diversity.

Results: The EBF rate for infants up to the age of six months was $12 \%$. Mothers who delivered full-term babies were most likely to initiate breastfeeding within the first hour of delivery. More than a third of the mothers had ceased breastfeeding by one month $(40 \%, n=23)$. The introduction of complementary food took place in $17 \%$ of infants during this first month. The minimum standards of dietary diversity were met by one infant only. Different reasons found to influence mothers' feeding practices included needing to return to work (29\%) or their studies (12\%), the mothers' health status (25\%), and perceptions of an "insufficient" milk supply (13\%).

Conclusion: Therefore, new strategies should address these gaps in knowledge with key breastfeeding awareness messages and a special focus on community involvement and participation. There is also a need for the whole nutrition fraternity, including government, academia and development industries, to intervene by developing more innovative approaches to increase the rate of EBF in South Africa.

(P) Peer reviewed. (Submitted: 2015-05-15. Accepted: 2015-09-05.) ๑ SAJCN

S Afr J Clin Nutr 2015;28(4):170-179

\section{Introduction}

Breastfeeding is a primary strategy used to enhance infant nutrition ${ }^{1}$ and to improve child survival ${ }^{2}$ worldwide. The World Health Organization (WHO) recommends that mothers should practise exclusive breastfeeding (EBF) for the first six months of the infant's life, with the timely introduction of complementary food thereafter, and continued supplementary breastfeeding for up to two years and beyond. ${ }^{3,4}$ South Africa supports this recommendation, as shown by the resolution of the 2011 Tshwane declaration for the support of breastfeeding. ${ }^{4}$ Complementary food should be introduced once an infant reaches the age of six months when breast milk no longer meets the infant's evolving nutritional requirements. The WHO also recommends breastfeeding on demand, i.e. as often as the child wants, during the day and night.
While EBF is an uncommon practice in South Africa for the entire first six months, ${ }^{2,5}$ the country has been shown to have very high breastfeeding initiation rates (75-97\%). ${ }^{6}$ However, it appears that this is not maintained, as the 1998 and 2003 South African Demographic and Health Surveys showed that only $10 \%$ and $12 \%$ of infants aged 0-3 months, respectively, were exclusively breastfed, while EBF was even lower in infants aged 4-6 months (1\% and $2 \%$, respectively). ${ }^{2}$ Very low cumulative EBF rates of $7 \%$ at $0-5$ months (1998) and $8 \%$ at 0-6 months (2003) were also reported in both surveys. In 2008, Shisana et $\mathrm{al}^{7}$ reported that the cumulative EBF rate for the first six months had increased to $26 \%$ in South Africa. The cumulative EBF rate could be referred to as the "prevalence" indicator, i.e. the percentage of all children aged $\leq 6$ months who are exclusively breastfed at a point in time. This would commonly yield a higher 
percentage than a more direct indicator of duration, and could easily be misunderstood, thereby exaggerating the amount of EBF being practised. ${ }^{8}$ These EBF rates decreased in 2012. However, according to the South African National Health and Nutrition Examination Survey (SANHANES-1), only $7 \%$ of children aged $\leq 6$ months were exclusively breastfed. ${ }^{9}$

Furthermore, the early introduction of supplementary feeds ${ }^{5}$ and mixed feeding ${ }^{2}$ are the most common infant-feeding practices in South Africa. In 2014, according to the SANHANES-1 survey, ${ }^{9}$ the average age for the introduction of solid food in the country was 4.5 months. In addition, more than two thirds (64\%) of children were given solid or semi-solid food before the age of six months. ${ }^{9}$ Both of these feeding practices carry a high risk of infections, ${ }^{10}$ diarrhoea ${ }^{11}$ and malnutrition, ${ }^{2}$ as well as reducing the amount of breast milk consumed by infants. ${ }^{5}$

Despite efforts to improve infant and young child feeding, a mother's selection of appropriate feeding practices is greatly influenced by various spheres of life, including the support provided by formal health services and other community-based groups, ${ }^{1,12}$ the mother's attitude towards and perception of breastfeeding and its nutritional value, as well as the satiety of the infant. ${ }^{1,5}$ Levels of appropriate feeding practices have also declined in many other parts of the world, including other low-middle income countries. ${ }^{6}$ These feeding practices are dependent upon a vast number of economic, social and cultural factors. ${ }^{6,10,13}$ However, there is limited information on how these choices are made in South Africa. Accordingly, this research was carried out as an update on the current EBF rates and feeding practices of mothers in four provinces of South Africa. The data could also be used to monitor breastfeeding rates in the country.

A summary of exclusive breastfeeding data and the age of introduction of complementary food in South Africa, as recorded in different areas since 2003, is presented in Table I.

The high prevalence of human immunodeficiency virus (HIV) in the different populations of mothers within the South African context was another complicating factor. Therefore, in 2010, the WHO revised its infant-feeding guidelines in the context of HIV, and recommended that HIV-positive mothers should exclusively breastfeed their infants while receiving antiretroviral treatment for mothers, or prophylaxis for their infants. ${ }^{24}$ The WHO also recommends that HIV-infected mothers should completely avoid breastfeeding only if replacement feeding is acceptable, feasible, affordable, sustainable and safe. ${ }^{3,24}$

In a pledge to reduce mortality in children aged $\leq 5$ years, the intended outcome of the 2014 International Conference on Nutrition Rome Declaration on Nutrition and the Post-2015 Development

Table I: A summary of exclusive breastfeeding rates in South Africa

\begin{tabular}{|c|c|c|c|c|c|c|}
\hline Reference & Year* & Area & Sample size (n) & Population and context & $\begin{array}{l}\text { EBF up to six } \\
\text { months (\%) }\end{array}$ & $\begin{array}{l}\text { Age at which } \\
\text { solids were } \\
\text { introduced }\end{array}$ \\
\hline \multirow[t]{2}{*}{ Kruger and Gericke ${ }^{14}$} & \multirow[t]{2}{*}{2003} & \multirow[t]{2}{*}{ Pretoria } & \multirow[t]{2}{*}{144} & Mothers and caregivers & \multirow[t]{2}{*}{ Rarely practised } & \multirow[t]{2}{*}{ 2-3 months } \\
\hline & & & & Children aged $\leq 36$ months & & \\
\hline Mamabolo et al ${ }^{5}$ & 2004 & Limpopo & 276 & Mothers at randomly selected clinics & 4.1 & 1 month \\
\hline Maclntyre et al ${ }^{15}$ & 2005 & Gauteng & 150 & Mothers attending a postnatal clinic & 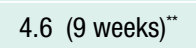 & 5 weeks \\
\hline $\mathrm{SADHS}^{16}$ & 2007 & South Africa & 2120 & Nationally representative sample & 8.0 & $<2$ months \\
\hline Faber and Benadé 17 & 2007 & KwaZulu-Natal & 505 & $\begin{array}{l}\text { Mothers and caregivers in a rural area in } \\
\text { KwaZulu-Natal }\end{array}$ & 11.0 (4 months) & 3.3 months \\
\hline Mushapi et $\mathrm{al}^{10}$ & 2008 & Limpopo & 185 & Mothers at randomly selected clinics & $7.6^{* *}$ & 2 months \\
\hline UNICEF $^{18}$ & 2008 & South Africa & National & Nationally representative sample & $7.0^{* * *}$ & Not reported \\
\hline Shisana et al ${ }^{7}$ & 2010 & South Africa & 508 & $\begin{array}{l}\text { People of all ages living in South African } \\
\text { households }\end{array}$ & 25.7 & Birth \\
\hline Ladzani et al $^{19}$ & 2010 & Mpumalanga & 815 & $\begin{array}{l}\text { HIV-positive women at randomly selected } \\
\text { clinics }\end{array}$ & $35.6^{* *}$ & 3 months \\
\hline Goga et al ${ }^{20}$ & 2012 & PMTCT sites & 783 & Mothers at purposively selected PMTCT sites & 16.0 & 3 weeks \\
\hline Van der Merwe ${ }^{21}$ & 2012 & Eastern Cape & 218 & Mothers attending a postnatal clinic & 35.7 & 45 days \\
\hline Shisana $^{9}$ & 2013 & South Africa & 243 & Individuals of all ages living in South Africa & 7.0 & 3 months \\
\hline $\begin{array}{l}\text { Kassier and } \\
\text { Veldman }\end{array}$ & 2013 & Free State & 189 & $\begin{array}{l}\text { Mothers and caregivers at randomly selected } \\
\text { households }\end{array}$ & Not reported & 2 months \\
\hline Osborne ${ }^{22}$ & 2013 & Eastern Cape & 43 & $\begin{array}{c}\text { Mothers and grandmothers at two selected } \\
\text { rural villages }\end{array}$ & $2.0^{* *}$ & 1 month \\
\hline Goosen et $\mathrm{al}^{23}$ & 2014 & Western Cape & 140 & $\begin{array}{c}\text { Primary caregivers from randomly selected } \\
\text { households }\end{array}$ & $6.0^{* *}$ & 3 months \\
\hline \multicolumn{7}{|c|}{$\begin{array}{l}\text { EBF: exclusive breastfeeding, HIV: human immunodeficiency virus, PMTCT: preventi } \\
\text { Children's Fund } \\
{ }^{\star} \text { Of publication } \\
\text { *^ The exclusive breastfeeding calculation included all of the infants in the study } \\
{ }^{\star \star \star} \text { Data refer to years other than those specified in the column heading }\end{array}$} \\
\hline
\end{tabular}


Agenda is to increase the rate of EBF in the first six months up to at least $50 \%$.

\section{Method}

\section{Research setting and study population}

This was a cross-sectional descriptive study, which was part of a larger study in which violations of the International Code of Marketing of Breast-milk Substitutes in four provinces in South Africa were explored. The target population included mothers and/or caregivers of infants aged 0-6 months, as well as pregnant women at selected health facilities in four provinces (North West, Gauteng, Free State and Eastern Cape). A random sample of 8-12 health facilities was drawn from each of the four provinces. Health facilities were ranked according to the size of the facility, and by district and subdistrict. Only facilities in which more than 7500 antenatal and postnatal visits were recorded in 2011 were considered to be large enough for inclusion. In total, 40 health facilities were randomly selected and visited in the four provinces, including metropolitan and nonmetropolitan health facilities across the geographical area of each province. Eight facilities each were selected from two provinces (North West and Free State), and 12 facilities each from the other two provinces (Gauteng and Eastern Cape) because of the higher number of clinics in these provinces. The target sample for the larger study was at least 20 pregnant women, mothers and/or caregivers of infants aged $\leq 6$ months per health facility (a total of 800 participants). The research was conducted and the data collected between May and November 2013.

To investigate EBF rates in this study, the target population consisted only of mothers and/or caregivers $(n=580)$, but not pregnant women. Therefore, the term "mothers" will be used in this paper to refer to the target population.

\section{Study sample}

On arrival at each of the 40 selected health facilities, the first 20 participants who met the inclusion criteria and gave informed consent to take part were enrolled to be interviewed. The use of convenience sampling within each facility was necessitated owing to practical considerations, such as the days on which mothers with infants visited the clinic, as well as the distances between the facilities. If 20 participants were not recruited at the selected health facility, sampling was carried out in two alternative clinics in close proximity.

\section{Data collection tools}

Data collection and fieldwork were completed by the core study team, including individuals with appropriate local language skills. Data were collected using a standardised questionnaire for the mothers of infants aged $\leq 6$ months. Piloting was conducted before the start of the main study at a health facility in North West province which was not included in the main study in order to adapt and enhance the research tools in preparation for the study, and to test the procedures at health facility level. Fieldworkers were trained on the use of the questionnaires and interviewing prior to data collection in the field.
Each member of the team was fluent in English and at least one of the two languages most widely spoken in the province. As there are 11 official languages, only two of the predominant languages in each of the provinces were used.

A fixed-structured interview was conducted with each participant in her preferred language. The questionnaire included both open- and closed-ended questions. Dietary intake and diversity were assessed through completion by the mothers of 24-hour recall, based on the Food and Agriculture Organization of the United Nations (FA0) dietary diversity list, consisting of 12 different food groups. ${ }^{25}$ The list was adapted to include local foods and food traditionally consumed in the four provinces.

\section{Data analysis}

Epi Info ${ }^{\mathrm{TM}}$ version 7.6 was used for data entry. Double-data entry was employed to ensure data quality. Prior to analysis, data were checked for missing values and inconsistencies, and cleaned to ensure quality and consistency. Qualitative data were grouped into various themes and coded before analysis.

Statistical analysis was carried out using SPSS $^{\circledR}$ version 21.0. Descriptive statistics and frequencies were used. Cross-tabulations and Pearson's chi-square test were used to assess the relationship between groups. The level of statistical significance was set at a $p$-value of less than 0.050 . Odds ratios were calculated from the frequency tables. Dietary intake and diversity were assessed and analysed according to the FAO dietary diversity list. The infants' ages were recorded in weeks. The data were then recoded into months. The age category of one month was infants aged 1-4 weeks; the category of two months, infants aged 5-8 weeks; three months, infants aged 9-12 weeks; four months, infants aged 13-16 weeks; five months, infants aged 17-20 weeks; and six months, infants aged 21-24 weeks. The six-month EBF rate was calculated using the following formula:

\section{Six-month EBF rate $=$ infants (in their sixth month of life) who received only breast milk the previous day}

Total number of infants (six months old)

\section{Ethical approval}

The Human Research Ethics Committee of North-West University approved the research protocol (Ethics Number NWU-00008-13-A1). Written informed consent forms were signed by the participants after they had been verbally informed of the purpose of the research. Confidentiality was ensured by not asking for participants' names or any other identification. Participants were required to sign an informed consent form before participating in the study. The National Department of Health gave permission for the research, informed the provinces of the survey, and requested their cooperation. Access to the individual facilities was secured by the research team.

\section{Results}

The health facilities that were included, and the total number of mothers interviewed, for the study, are listed in Table II. 
Table II: Participant representation per selected health facility

\begin{tabular}{|c|c|c|c|}
\hline Province & District & Facility & $\begin{array}{l}\text { Total number } \\
\text { of mothers } \\
(n=580)\end{array}$ \\
\hline \multirow[t]{9}{*}{ North West $(n=138)$} & \multirow[t]{2}{*}{1} & 1 & 5 \\
\hline & & 2 & 5 \\
\hline & \multirow[t]{4}{*}{2} & 3 & 29 \\
\hline & & 4 & 13 \\
\hline & & 5 & 3 \\
\hline & & 6 & 5 \\
\hline & \multirow[t]{3}{*}{3} & 7 & 3 \\
\hline & & 8 & 22 \\
\hline & & 9 & 13 \\
\hline \multirow[t]{8}{*}{ Free State $(n=175)$} & 4 & 10 & 13 \\
\hline & \multirow[t]{3}{*}{5} & 11 & 23 \\
\hline & & 12 & 16 \\
\hline & & 13 & 25 \\
\hline & \multirow[t]{4}{*}{6} & 14 & 2 \\
\hline & & 15 & 11 \\
\hline & & 16 & 15 \\
\hline & & 17 & 15 \\
\hline \multirow[t]{11}{*}{ Gauteng ( $n=250$ ) } & \multirow[t]{2}{*}{7} & 18 & 13 \\
\hline & & 19 & 44 \\
\hline & \multirow[t]{4}{*}{8} & 20 & 12 \\
\hline & & 21 & 17 \\
\hline & & 22 & 15 \\
\hline & & 23 & 7 \\
\hline & \multirow[t]{4}{*}{9} & 24 & 10 \\
\hline & & 25 & 15 \\
\hline & & 26 & 28 \\
\hline & & 27 & 15 \\
\hline & 10 & 28 & 10 \\
\hline \multirow[t]{12}{*}{ Eastern Cape $(n=332)$} & \multirow[t]{5}{*}{11} & 29 & 20 \\
\hline & & 30 & 9 \\
\hline & & 31 & 19 \\
\hline & & 32 & 19 \\
\hline & & 33 & 13 \\
\hline & \multirow[t]{2}{*}{12} & 34 & 20 \\
\hline & & 35 & 23 \\
\hline & \multirow[t]{5}{*}{13} & 36 & 6 \\
\hline & & 37 & 15 \\
\hline & & 38 & 12 \\
\hline & & 39 & 6 \\
\hline & & 40 & 14 \\
\hline \multicolumn{2}{|c|}{ Total number of participants } & & 580 \\
\hline
\end{tabular}

Table III: Socio-demographic characteristics and exclusive breastfeeding rates at the time of the study

\begin{tabular}{|c|c|c|c|}
\hline Characteristics & Total, $\mathbf{n}(\%)$ & EBF; $n(\%)$ & Non-EBF;", n (\%) \\
\hline \multicolumn{4}{|l|}{ Place of birth } \\
\hline Hospital & $419(72)$ & $185(44)$ & $234(56)$ \\
\hline Clinic & $140(24$ & $72(51)$ & $68(49)$ \\
\hline Home & $21(4)$ & $9(43)$ & $12(57)$ \\
\hline \multicolumn{4}{|l|}{ Type of delivery } \\
\hline Vaginal & $440(76)$ & $197(45)$ & $243(55)$ \\
\hline Caesarean & $125(22)$ & $65(51)$ & $60(49)$ \\
\hline Complications ${ }^{* * *}$ & $15(3)$ & $4(27)$ & $11(73)$ \\
\hline \multicolumn{4}{|c|}{ Relationship to infant } \\
\hline Mother & $551(95)$ & $266(48)$ & $285(52)$ \\
\hline Caregiver & $29(5)$ & $0(0)$ & $29(100)$ \\
\hline \multicolumn{4}{|l|}{ Age distribution } \\
\hline 1 month & $81(14)$ & $75(93)$ & $6(7)$ \\
\hline 2 months & $159(27)$ & $98(62)$ & $61(38)$ \\
\hline 3 months & $107(19)$ & $56(52)$ & $51(48)$ \\
\hline 4 months & $62(11)$ & $21(34)$ & $41(66)$ \\
\hline 5 months & $46(8)$ & $11(24)$ & $35(76)$ \\
\hline 6 months & $34(6)$ & $4(12)$ & $30(88)$ \\
\hline \multicolumn{4}{|l|}{ Time of delivery } \\
\hline Premature & $81(14)$ & $41(51)$ & $40(49)^{+\ldots+m}$ \\
\hline Full term & $499(86)$ & $225(45)$ & $274(55)^{\prime}$ \\
\hline \multicolumn{4}{|c|}{ Breastfeeding initiation $(n=490)$} \\
\hline Within 1 hour & $441(90)$ & $236(54)$ & $205(46)$ \\
\hline Later & 49 (10) & $30(61)$ & 19 (39) \\
\hline
\end{tabular}

EBF: exclusive breastfeeding

* EBF means no food or drink (not even water), except breast milk

** Non-EBF means infants not breastfeeding at all, or those predominantly breastfeeding

*** Complications with either vaginal or Caesarean deliveries

**** Association between the time of delivery and breastfeeding initiation (p-value 0.000 odds ratio 6.2)

${ }^{\star \star \star \star \star ~ C o m p a r i s o n ~ b e t w e e n ~ e x c l u s i v e ~ b r e a s t f e e d i n g ~ a n d ~ n o n-e x c l u s i v e ~ b r e a s t f e e d i n g ~}$ (p-value 0.354)

\section{Socio-demographic characteristics}

The socio-demographic data are summarised in Table III. In total, 580 mothers were interviewed. The mean age of the infants was 2.9 \pm 1.5 months. Only $14 \%$ of the infants were $\leq 1$ month old, and less than $10 \%$ were aged $\geq 5$ months.

\section{Breastfeeding practices}

\section{Breastfeeding initiation}

Most ( $n=490,85 \%$ ) of the mothers were breastfeeding at the time that the study was conducted, and of these, $90 \%$ initiated breastfeeding during the first hour of delivery. The remaining $10 \%$ initiated breastfeeding a day after delivery. The number of children being exclusively and non-exclusively breastfed at the time of the study, according to the different socio-demographic characteristics, is demonstrated in Table III. Early breastfeeding initiation did not significantly affect the chances of being exclusively breastfed 


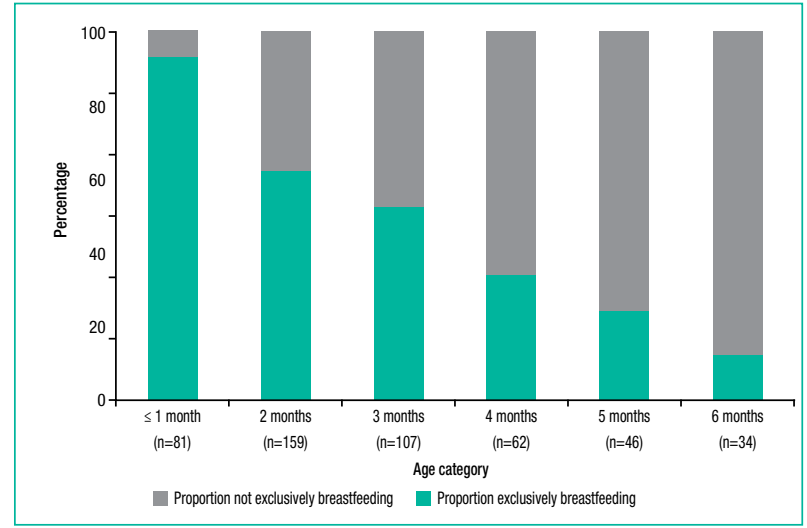

Figure 1: Exclusive breastfeeding rates according to age category $(\mathrm{n}=266)$ ARV: antiretroviral, HIV: human immunodeficiency virus

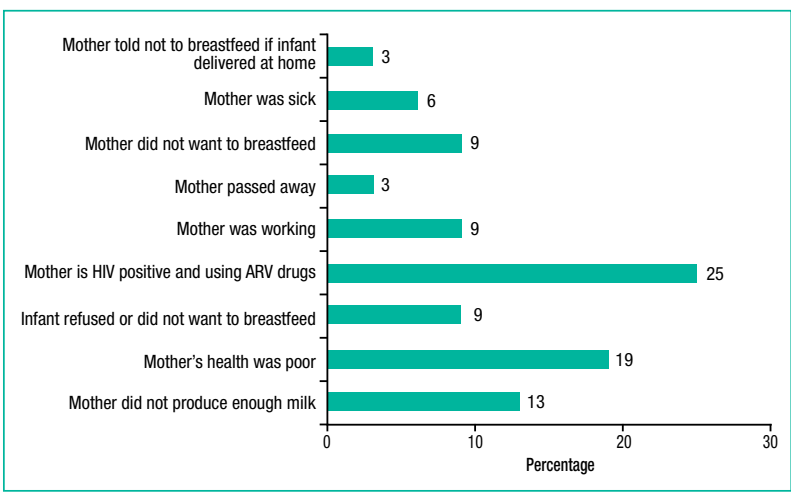

Figure 2: Reasons given by mothers for not breastfeeding their infants $(\mathrm{n}=32)$

(p-value 0.740). However, mothers who delivered full-term babies were most likely to initiate breastfeeding within the first hour of delivery. Being born full term or prematurely did not significantly affect the EBF rate at the time that the study was conducted ( $p$-value 0.354).

\section{Exclusive breastfeeding}

The percentage of mothers practising EBF at the time of the study was $48 \%$ ( $n=266$ of 580$)$. The mean age of infants being exclusively breastfed was 2 months (8.3 weeks). The decrease in the EBF rate over time is clearly shown in Figure 1.

Only four of the 34 mothers interviewed at 6 months (12\%) had exclusively breastfed for six months at the time that the study was conducted. However, $6 \%$ (32 of 580 ) of the mothers did not breastfeed their infants at all. The mother's HIV status was the most common reason given for this. Other reasons provided by mothers for never breastfeeding are summarised in Figure 2.

\section{Breastfeeding cessation}

Of the mothers who had stopped breastfeeding, $(n=58) 40 \%$ ceased doing so within one month of the birth of their infant. Breastfeeding cessation practices according to the age of the infant (grouped according to category) are shown in Figure 3. The most important reason for cessation was that the mother had to return to work.

The different reasons given for breastfeeding cessation are also summarised in Figure 4.

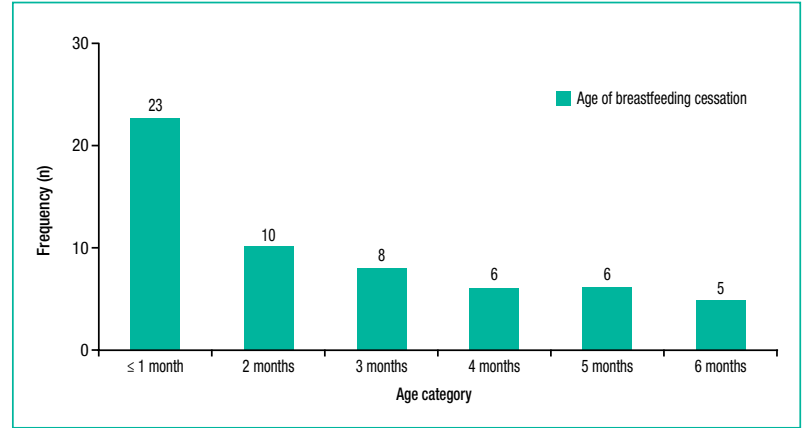

Figure 3: Breastfeeding cessation practices of mothers according to the age of the infant, grouped according to category $(n=58)$

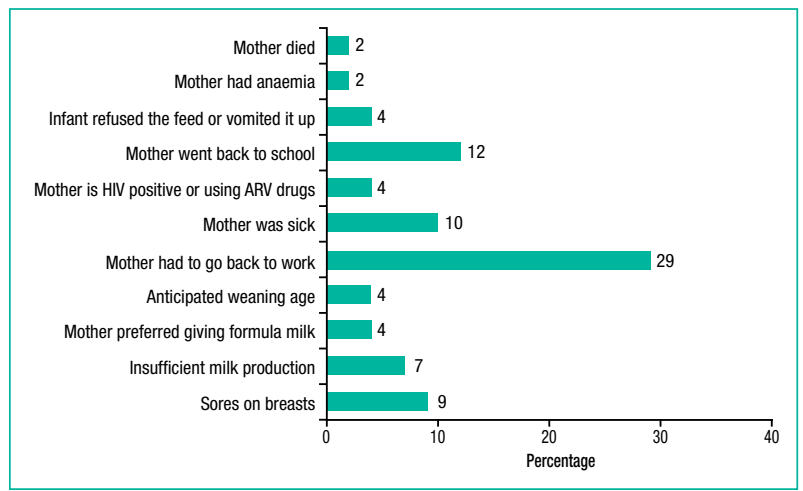

ARV: antiretroviral, HIV: human immunodeficiency virus

Figure 4: Reasons given by mothers for breastfeeding cessation at the time of the study $(n=58)$

Table IV: Mothers' perceptions of the importance of breastfeeding

\begin{tabular}{|l|c|}
\hline The importance of breastfeeding & $\mathbf{n}=580$ \\
\cline { 2 - 2 } & $\mathbf{n}(\%)$ \\
\hline Breast milk contains adequate nutrients for the infant & $239(41)$ \\
\hline Breast milk protects the infant from infections and illness & $159(27)$ \\
\hline Breastfeeding is economical & $50(9)$ \\
\hline Breastfeeding helps the mother and infant to bond & $44(8)$ \\
\hline Do not know & $33(6)$ \\
\hline Breast milk makes the infant grow strong and well & $28(5)$ \\
\hline $\begin{array}{l}\text { Breast milk is clean, warm, best, and natural food for the } \\
\text { infant }\end{array}$ & $12(2)$ \\
\hline Breast milk is always available and is convenient to give & $15(3)$ \\
\hline
\end{tabular}

\section{Mothers' perceptions of the importance of breastfeeding}

Interviewed mothers were asked why they thought that breastfeeding was important. More than a third ( $41 \%$ ) said that breast milk contains adequate nutrients for the child. Only $6 \%$ of the mothers did not know. The different perceptions of the importance of breastfeeding, as reported by the mothers, are highlighted in Table IV.

\section{The practices of mothers who did not perform exclusive breastfeeding}

At the time of the study, 314 (54\%) mothers were not exclusively breastfeeding, and gave other liquids or food to their infants. Nearly half $(n=154,49 \%)$ of the mothers gave their infants infant-feeding 


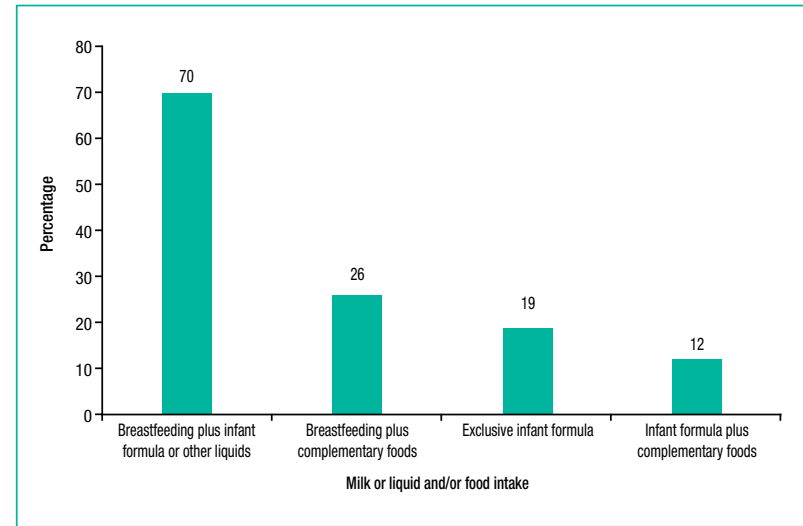

Figure 5: The feeding practices of mothers who did not exclusively breastfeed their infants at the time that the study was conducted $(n=314)$

Table V: Reasons offered by the mothers for giving their infants other liquid and/or food

\begin{tabular}{l|c|}
\hline Reason & $\mathbf{n}=314$ \\
\cline { 2 - 2 } & $\mathrm{n}(\%)$ \\
\hline Breast milk alone was insufficient & $95(30)$ \\
\hline The mother had to return to work & $23(7)$ \\
\hline The infant was thirsty all the time & $19(6)$ \\
\hline There was insufficient milk production & $14(5)$ \\
\hline The mother had to return to her studies & $11(4)$ \\
\hline The mother was advised to do so by a family member & $10(3)$ \\
\hline The mother was ill & $9(3)$ \\
\hline The mother (incorrectly) believed that the consumption of & $6(2)$ \\
\hline water would keep the baby's navel free of infection & \\
\hline The mother was on antiretroviral drugs or was HIV positive & $6(2)$ \\
\hline The mother was advised to do so by a health practitioner & $5(2)$ \\
\hline HIV: human immunodeficiency virus &
\end{tabular}

formula, whereas only $3(1 \%)$ gave cow's milk, 99 (32\%) water, $7(2 \%)$ tea, and $3(0.9 \%)$ other unspecified liquids.

The different feeding practices of the mothers who were not exclusively breastfeeding are shown in Figure 5 . The majority ( $n=220,70 \%$ ) of the mothers gave either infant-feeding formula or other liquids (water, tea or juice), in addition to breast milk, to their infants. Nearly a fifth $(n=59,19 \%)$ of the mothers fed their infants formula exclusively.

Nearly a third $(n=95,30 \%)$ of the mothers gave their infants milk, and other liquid and/or food because they believed that their breast milk alone was insufficient, while $23(7 \%)$ mothers gave other foods because they had to return to work. The top 10 reasons for feeding their infants other food or liquids are given in Table $\mathrm{V}$.

\section{Dietary intake}

Twenty-four hour recall was completed by both the EBF $(n=266)$ group and the non-EBF group $(n=314)$. This was performed as part of a validating procedure to ensure that mothers who reported exclusively breastfeeding their infants actually did so, and did not offer them water or other liquids too. Of the mothers who were not

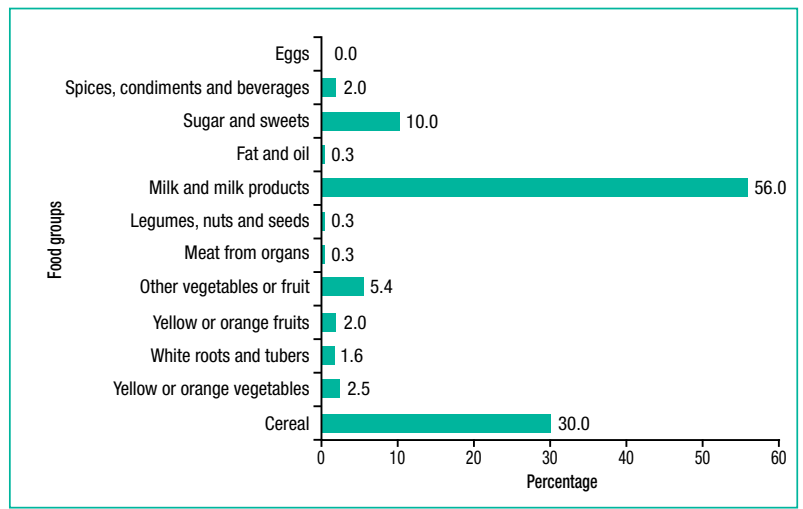

Figure 6: The dietary intake of infants who were not exclusively breastfed, according to the Food and Agriculture Organization of the United Nations dietary diversity list $(n=314)$

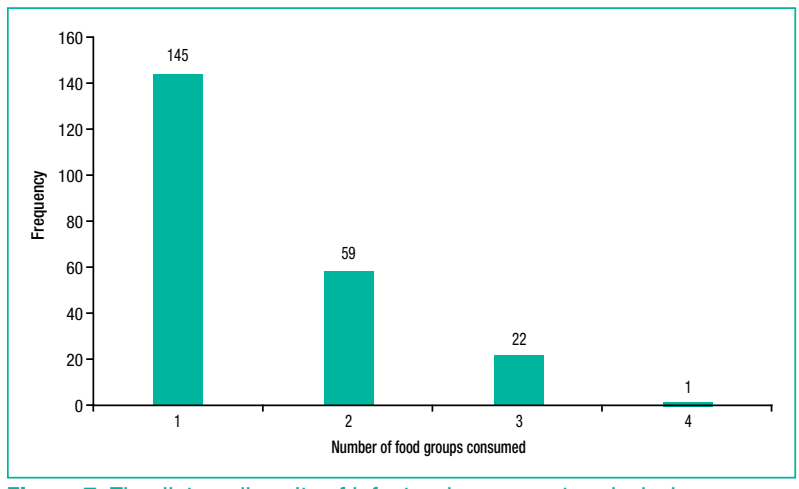

Figure 7: The dietary diversity of infants who were not exclusively breastfed, according to the Food and Agriculture Organization of the United Nations dietary diversity list $(\mathrm{n}=314)$

exclusively breastfeeding, the majority $(n=247,93 \%)$ reported that the diet recall was typical of what the infant ate or drank on a daily basis. The dietary intake of infants categorised according to the different food groups in the FAO dietary diversity list (this list does not include breast milk) is shown in Figure 6. None of the mothers gave their infants food from the following food categories: dark green leaves, meat and poultry (fleshy meat), eggs, and fish and seafood. More than half $(n=175,56 \%)$ of the mothers predominantly gave their infants fortified infant-feeding formula. Ten per cent $(n=31)$ gave them sugar and sweets. This group of foods included sugar added to tea, water or milk feeds.

\section{Dietary diversity}

The standard for minimum daily dietary diversity was achieved if infants consumed four or more food groups from the FAO dietary diversity list of 12 food groups. The dietary diversity of the infants who were not exclusively breastfed is demonstrated in Figure 7. Only one infant met the standards for minimum dietary diversity. The majority of the infants consumed food from only one group.

\section{The introduction of milk, liquids and semi-solid or solid food}

For the purposes of this study, the first drink that was given to the infant was defined as any fluid or liquid other than breast milk. The different stages of the introduction of infant-feeding formula, the first drink (other than breast milk) and complementary food, according to the different ages of the infants (grouped according to category) is 


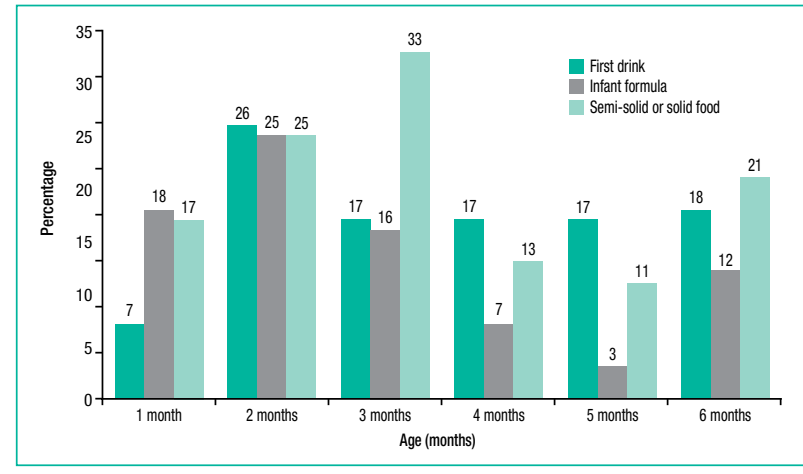

Figure 8: The introduction of infant formula, liquids and semi-solid or solid food to infants who were not exclusively breastfed

shown in Figure 8. The sample size comprised mothers who were not exclusively breastfeeding their infants $(n=314,54 \%)$ at the time that the interviews were conducted. Significantly more mothers ( $n=122,39 \%$ ) reported that infant-feeding formula was the first drink, besides breast milk, that was given to their infants ( $p$-value $<0.000$, while $62(20 \%)$ said that water was the first drink. Nearly half $(n=150,48 \%)$ of the mothers added sugar to the milk feeds and to drinks. Furthermore, $176(56 \%)$ of the mothers used a bottle to feed their infants, 27 (9\%) practised cup feeding, and 21 (7\%) spoon fed their infants. Nearly two thirds $(n=195,62 \%)$ reported that their infants had consumed fluid or liquid from a bottle the night before the day on which the interviews were conducted.

More than a third $(n=116,37 \%)$ of the mothers in the non-EBF group introduced complementary food (semi-solid or solid) to their infant when they were aged between one and six months, as shown in Figure 8. A third (33\%) of the mothers introduced complementary food when the infant was three months of age. Nearly half $(n=131$, $42 \%)$ reported giving food to their infant between one and six times a day. The mean was $2.5 \pm 1.1$ times a day. Twenty $(7 \%)$ mothers reported that their infant ate semi-solid or solid food once a day, $53(17 \%)$ said that this occurred twice a day, $46(15 \%)$ three times a day, $7(2 \%)$ four times a day, $4(1 \%)$ five times a day, and $2(1 \%)$ six times a day.

\section{Discussion}

Nearly half of the mothers were exclusively breastfeeding at the time of the study, and $12 \%$ continued to do so until their infant was six months. While this is considerably below the 2014 International Conference on Nutrition Rome Declaration on Nutrition and Post2015 Development Agenda target rate of 50\% EBF for the first six months of the infant's life, the results of this cross-sectional study are in agreement with other South African studies in which breastfeeding practices were evaluated. ${ }^{5,10,15,19,26}$ Our finding that the breastfeeding initiation rate within the first hour of delivery was very high suggests that the early initiation of breastfeeding following delivery, as recommended by the WHO, is being practised across these four provinces.

In addition, the findings showed that the stage of delivery (in this case, full-term delivery) was significantly associated with early breastfeeding initiation. Most of the mothers who delivered full-term babies were most likely to initiate breastfeeding within the first hour of delivery. However, a statistically significant association between the type of delivery and the likelihood of exclusively breastfeeding was not demonstrated by the results. This is in contrast to a study in which it was shown that vaginal delivery was associated with a higher breastfeeding rate. ${ }^{18}$ The location of delivery also seemed to influence EBF practices as nearly $5 \%$ of the mothers reported that they were advised by healthcare professionals not to breastfeed if their infant was delivered at home.

The EBF rate of $12 \%$ for infants aged six months in the current study is relatively higher than that reported in studies conducted in other parts of the country. ${ }^{5,9,10,15,27,23}$ On the other hand, the findings in this study on the rate of EBF, although lower in comparison with studies conducted elsewhere in the country, showed that the EBF rate decreased from one month onwards, hence the very low EBF rate at six months. In this regard, EBF over a lengthy period still remains uncommon within South Africa, and strategies are needed to promote $\mathrm{EBF}$ initiation and maintenance.

Previous research shows that strategies which do not engage important family members, like grandmothers, in supporting breastfeeding are likely to fail. ${ }^{27}$ Therefore, the MomConnect programme, recently launched by the South African Department of Health, could be an effective intervention in promoting EBF and providing support to pregnant mothers and mothers-to-be during pregnancy, after delivery and beyond. In order to achieve the global target of increasing the EBF rate up to at least $50 \%$ during the first six months (2014 International Conference on Nutrition Rome Declaration on Nutrition and Post-2015 Development Agenda), the WHO also recommends that mothers should avoid using bottles, teats or pacifiers, and should instead breastfeed on demand, i.e. as often as the infant wants, day and night. Such messages should be communicated to mothers through breastfeeding counselling, which has been shown to be an effective intervention in improving EBF rates. It was also reported in one study ${ }^{21}$ that higher rates of $E B F$ may have been influenced by the fact that mothers report that they are exclusively breastfeeding, even when giving water to their infant. Solutions to this problem may include further education and breastfeeding awareness. Twenty-four hour recall was used in this study to validate whether or not mothers were exclusively breastfeeding, and not giving water, or other liquid or foods to their infant.

The calculation of the EBF rate for six months is a variable which could possibly contribute to the disparity in EBF rates reported in the studies. To assess the EBF rate, an indicator defined as the percentage of children aged $\leq 6$ months who are being exclusively breastfed at a point in time is used. However, this indicator actually describes the prevalence of EBF, that is, whether children aged $\leq 6$ months are currently being exclusively breastfed at the time that the survey is conducted. ${ }^{8}$ The EBF recommendation is that every child should be exclusively breastfed until they reach the six-month anniversary of their birth, that is, for the full duration of six months. 
Therefore, according to the method used in this study, the actual duration of EBF was assessed, as it is calculated by including only infants in their sixth month of life. The formula used in this study is now illustrated (other studies in which similarly low EBF rates were reported $^{5,9,20,21}$ used this same method of calculation):

Six-month EBF rate $=$ infants (in their sixth month of life) who received only breast milk the previous day

Total number of infants (six months old)

However, this method of calculation differs from the methods used in two other studies ${ }^{10,15,23}$ in which higher EBF rates at six months of age were reported using the following method of calculation, and included the entire sample of infants aged $\leq 6$ months old:

\section{EBF rate $=$ infants (0-6 months of age) who received only breast} milk the previous day

Total number of infants included in the study

Thus, the extent to which EBF is practised up to six months using appropriate and accurate indicators in order to promote EBF for the recommended six months.

Although the total number of mothers who chose not to breastfeed at all was very low in this study, the most cited reasons for this were the mothers' HIV status and poor maternal health. These results suggest that the resolutions contained within the Tshwane declaration may not have been effectively implemented. Despite the generally high level of HIV awareness, mothers still demonstrated an unclear understanding that they could breastfeed their infant, regardless of their HIV status. ${ }^{20,26,28,29}$ In addition, some mothers reported that they did not produce enough milk. This phenomenon is described as "insufficient milk syndrome", and it has been proposed that alternative explanations exist for this issue in cases when it is a "real" phenomenon. ${ }^{30}$ It may not be an excuse used by mothers to validate reasons for early breastfeeding cessation or early initiation of complementary food, but owing to lack of or insufficient contact between the mother and infant. A qualitative analysis of interviews indicated that the maternal experience of hunger contributes to perceived milk insufficiency, as do anxiety about infant hunger and a perception that access to adequate food is necessary for successful breastfeeding to occur. ${ }^{31}$ It was also reported in one study that in comparison with white and African American mothers, Hispanic mothers were most likely to use the perception of milk insufficiency as a reason for early breastfeeding cessation. ${ }^{32}$

Maternal depression and distress have been shown to be a significant predictor of reduced duration and exclusivity of breastfeeding in developed countries. ${ }^{32}$ Psychological stress, possibly associated with severe food insecurity and malnutrition, could impair milk let down, subsequent milk output and breast emptying in the developing country context. Physiological mechanisms which could potentially alter the concentration of certain fats and micronutrients, as well as breast milk output, include hunger, which can drive perceptions of the body's inability to produce sufficient milk. ${ }^{32}$
This may be a cause for concern, and is an issue which should be addressed by more in-depth education and breastfeeding awareness programmes. It was shown in the study by Hurley et $\mathrm{a}^{32}$ and other recent systematic reviews that breastfeeding education and community-based interventions significantly improved EBF rates in developing countries..$^{27,33,34}$ In addition, it was reported that mothers with a higher level of education or income were more likely to initiate breastfeeding, and to breastfeed for longer, than mothers with a lower level of education. ${ }^{29}$

Breastfeeding cessation was reported as early as one month of age in this study. The most often-stated reason was that the mother had to return to work. This could mean that mothers were either given insufficient maternity leave, or that self-employed mothers had no maternity leave at all. The findings of this study are similar to those which have been reported in several studies in which it was demonstrated that insufficient leave can influence a mother's choice of feeding practice. ${ }^{12,26,35,36}$ On the other hand, even if a mother has to return to work early, it is still possible to express breast milk and to leave it at home for the caregiver to administer, either with a cup or a spoon. The results of this study also showed that some mothers stopped breastfeeding because they had to go back to study. Programmes in which multi-component educational strategies for contraception and the prevention of teenage pregnancies were employed have been successful in the developing world. ${ }^{37}$ In this regard, going back to study would not be a reason for early breastfeeding cessation.

Evidently, the early introduction of food, mixed feeding and failure to breastfeed exclusively, remain major challenges in South Africa. Healthcare workers and mothers both need to be educated on the importance of exclusive breastfeeding and timing with regard to the appropriate initiation of complementary food. The findings of this study appear to be consistent with those in other studies in which the peak initiation of complementary food was demonstrated to occur as early as within the first month, ${ }^{21}$ at one month, ${ }^{5,15}$ and at two months. ${ }^{14}$ The most often-stated reason for the early initiation of complementary food was that the mothers' breast milk was "not enough" for the infant. Esterik ${ }^{38}$ proposes that human milk production is controlled by the infant's appetite, the frequency of milk removal and the mother's ability to produce milk. Therefore, it is suggested that a distinction should be made between the phenomenon when it occurs during EBF, and when it occurs once complementary feeding has begun. It could be referred to as a cultural phenomenon when it occurs during EBF, and as a largely physiological response to reduced nipple stimulation once complementary feeding has begun.

The dietary data indicated that infant-feeding formula was the fluid most commonly consumed. What was concerning in this study is that $10 \%$ of the mothers added sugar to some of the milk feeds and drinks which they introduced to the infants. The early introduction and consumption of sugar by infants may create a pattern of preference for sweet and fatty food, which can continue in later years. ${ }^{39} \mathrm{~A}$ third of the infants in this study were given maize meal porridge as the introductory complementary food. Homemade cereal or porridge 
was the second most frequently consumed food by infants in the SANHANES-1 study, and maize meal porridge remains among the top 10 consumed foods in South Africa. Maize meal porridge is not only bulky and of low nutrient density, but is also high in phytate, which inhibits zinc and iron absorption. ${ }^{17}$ It has been demonstrated in other studies that using cereal-based gruel is a common complementary feeding practice. ${ }^{6,10,40}$ Only one infant met the minimum dietary diversity standards in our study. Infants are at risk of becoming stunted if they do not receive sufficient dietary diversity with the introduction of complementary food. ${ }^{27}$ It has also been demonstrated that infants who are introduced to complementary feeding too early can self-regulate their energy intake by decreasing their breast milk consumption, and this can lead to abrupt breastfeeding cessation. ${ }^{20}$

Feeding practices influence infection and mortality. ${ }^{41} \mathrm{~A}$ causal association between early breastfeeding and reduced infectionspecific neonatal mortality in young infants was demonstrated in one study. ${ }^{42}$ It was proposed in another study ${ }^{43}$ that infants who had been breastfed for 4-6 months were at a lower risk of contracting respiratory or gastrointestinal tract infections in the first six months, compared to those who had never been breastfed. Breastfeeding for at least six months seems to have protective effects against respiratory and gastrointestinal tract infections during that period. This protective effect improves with a longer duration and with $\mathrm{EBF}^{44}$ These findings support health policy strategies which seek to promote EBF for the recommended period of six months. Therefore, promoting these programmes helps mothers to choose an appropriate infant-feeding practice and to commit to it, thereby potentially reducing the risk of infection in their infant.

Despite challenges to breastfeeding exclusively, the mothers in this study demonstrated a sound understanding of the importance of breastfeeding. They may have known and understood that breastfeeding is important, but may not have received the proper support and encouragement needed to breastfeed their infants. Schmied et $\mathrm{al}^{45}$ showed that peer support, and professional support and guidance were identified as very important elements of breastfeeding success. Although this was not investigated, in other studies ${ }^{1,40}$ an association between mothers' perceptions of breastfeeding and their choice of feeding practice were found.

Limitations of this study include the fact that there was a low number of six-month-old infants in this study. This is possibly because some of the mothers did not expect to be at the health facilities at the time of the study, especially if the specific infant day visit at the health facility was for six-week-old infants. Therefore, the age distribution may have been influenced by the age at which children were expected to visit the clinics. Thus, there might have been some bias in the study. In addition, although the main reason given for not breastfeeding at all was poor maternal health, the total number of mothers in that category was very low. Adequate insight into the context in which infants were fed infant formula in this study was not obtained. Thus, even though it is accepted that infant formula feeding or bottle feeding are not ideal methods of feeding infants aged $\leq 6$ months, they might have been the only choice available to many mothers who opted for this method of feeding their infants.

\section{Conclusion and recommendations}

A high breastfeeding initiation ratio, but a very low six-month EBF rate of $12 \%$, was demonstrated in this current study; far below the 2014 International Conference on Nutrition Rome Declaration on Nutrition and the Post-2015 Development Agenda target of 50\%. It was also shown in this study that some mothers may not have had a clear perception and understanding of the importance of breastfeeding. The early initiation of complementary food remains a problem in South Africa. There is not much diversity with respect to the food being given to infants from the different food groups, and the food that is consumed by infants is nutritionally inadequate, presenting additional risks to their well-being.

The most frequently stated reasons given by the mothers for not breastfeeding at all were having to return to work or their studies early, the mother's HIV status and poor maternal health. Therefore, healthcare professionals should conduct educational sessions in which mothers can participate, including sessions on how to maintain breastfeeding after returning to work or pursuing studies. Emphasis must also be placed on ARV drugs, and balancing the risks of not breastfeeding against the risks of HIV transmission.

Community-based strategies to educate teenagers, women and mothers on appropriate complementary foods for infants should be implemented. It is also important to ensure that practices and behaviour in healthcare settings always protect, promote and support breastfeeding. Possible strategies to increase exclusively breastfeeding for longer periods include family and community support groups, an increase in paid maternity leave days, further education and breastfeeding awareness. To reach the 2014 International Conference on Nutrition Rome Declaration on Nutrition and the Post-2015 Development Agenda goal of a rate of $50 \%$, the entire nutrition fraternity, including government, academia, industry and development agencies, needs to intervene and develop more innovative approaches, such as workplace support and interventions, as well as the use of mass media, to disseminate appropriate infantfeeding messages in order to increase the rate of EBF in South Africa.

\section{Acknowledgements}

The authors would like to extend their utmost gratitude to:

- The participants of the study, including the research team.

- Portia Mantwa, Ndugiselo Muravha, Priscilla Nkhesani, Noleen Mohononi, Johan du Plessis and Ronel Benson.

- Chantell Witten, for her invaluable support and effort.

- The health facility staff.

They also wish to thank the Centre of Excellence for Nutrition and Statistical Consultation Services, North-West University, Potchefstroom; the National Department of Health; and the organisation who provided the funding.

\section{Declaration}

This study was financially supported by the Centre of Excellence for Nutrition at North-West University. The fieldwork was performed at 


\section{the same time as the national compliance study of the Internationa Code of Marketing of Breast-milk Substitutes.}

\section{Conflicts of interest}

\section{The authors declare that they have no conflict of interest.}

\section{References}

1. Meedya S, Fahy K, Kable A. Factors that positively influence breastfeeding duration to 6 months: a literature review. Women and Birth. 2010;23(4):135-145.

2. ljumba P, Doherty $T$, Jackson D, et al. Social circumstances that drive early introduction of formula milk: an exploratory qualitative study in a peri-urban South African community. Matern Child Nutr. 2014;10(1):102-111.

3. World Health Organization. The optimal duration of exclusive breast feeding: a systematic review. Geneva: WHO, 2002.

4. Tshwane declaration for the support of breastfeeding in South Africa. S Afr J Clin Nutr. 2011;24(4):214

5. Mamabolo RL, Alberts M, Mbenyane GX, et al. Feeding practices and growth of infants from birth to 12 months in the central region of the Limpopo province of South Africa. Nutrition. 2004:20(3):327-333.

6. Ghuman MR, Saloojee H, Morris G. Infant feeding practices in a high HIV prevalence rural district of KwaZulu-Natal, South Africa. S Afr J Clin Nutr. 2009;22(2):74-79.

7. Shisana 0, Simbayi LC, Rehle T, et al. South African National HIV Prevalence, Incidence, Behaviour and Communication Survey, 2008: the health of our children. UNICEF [homepage on the Internet]. 2010. c2015. Available from: http://www.unicef.org/ southafrica/SAF_resources_hivprev08.pdf

8. Pullum TW. Exclusive breastfeeding: aligning the indicator with the goal. Glob Health Sci Pract. 2014;2(3):355-356.

9. Shisana 0. Report for UNICEF: data analysis on infant feeding practices, and anthropometry in children under five years of age: South Africa 2012. Human Sciences Research Council, 2013.

10. Mushaphi LF, Mbhenyane XG, Khoza LB, Amey AKA. Infant-feeding practices of mothers and the nutritional status of infants in the Vhembe District of Limpopo Province. S Afr J Clin Nutr. 2008;21(2):36-41

11. Kools EJ, Thijs C, Kester DMA, de Vries H. The motivational determinants of breast-feeding Predictors for the continuation of breast-feeding. Prev Med. 2006;43(5):394-401.

12. Kassier SM, Veldman FJ. Cry, the beloved bottle: Infant-feeding knowledge and the practices of mothers and caregivers in an urban township outside Bloemfontein, Free State province. S Afr J Clin Nutr. 2013;26(1):17-22.

13. Bland RM, Rollins NC, Coutsoudis A, Coovadia HM. Breastfeeding practices in an area of high HIV prevalence in rural South Africa. Acta Paediatrica. 2002;91(6):704-711

14. Kruger R, Gericke GJ. A qualitative exploration of rural feeding and weaning practices, knowledge and attitudes on nutrition. Public Health Nutr. 2003;6(2):217-223

15. Macintyre UE, de Villiers FPR, Baloyi PG. Early infant feeding practices of mothers attending a postnatal clinic in Ga-Rankuwa. S Afr J Clin Nutr. 2005;18(2):70-75

16. Department of Health, Medical Research Council, OrcMarco. South Africa Demographic Health Survey 2003. Pretoria: Department of Health, 2007.

17. Faber M, Benadé AJS. Breastfeeding, complementary feeding and nutritional status of 6-12-month-old infants in rural KwaZulu-Natal. S Afr J Clin Nutr. 2007;20(1):16-24.

18. United Nations Children's Fund. The state of the world's children: child survival. New York: Hattera Press, 2008

19. Ladzani R, Peltzer K, Mlambo MG, Phaweni K. Infant-feeding practices and associated factors of HIV-positive mothers at Gert Sibande, South Africa. Acta Paediatrica. 2011;100(4):538-542.

20. Goga AE, Doherty T, Jackson DJ, et al. Infant feeding practices at routine PMTCT sites, South Africa: results of a prospective observational study amongst HIV exposed and unexposed infants - birth to 9 months. Int Breastfeed J. 2012;7(1):4-14.

21. Van der Merwe S. Comparison of infant feeding practices in two health sub-districts with different baby friendly status in Mpumalanga province. Stellenbosch: Stellenbosch University, 2013.
22. Osborne N. Factors influencing infant feeding practices in the Transkei region, Eastern Cape Province, South-Africa. [Technical report for Master's degree]. Amsterdam: Vrije University, 2013

23. Goosen C, McLachlan MH, Schübl C. Infant feeding practices during the first 6 months of life in a low-income area of the Western Cape Province. South African Journal of Child Health; 8(2): 50-54.

24. World Health Organization. Breast is always best, even for HIV-positive mothers. BullWorld Health Organ. 2010;1(88):9-10.

25. Kennedy G, Ballard T, Dop MC. Guidelines for measuring household and individual dietary diversity. Food and Agriculture Organization of the United Nations; 2011.

26. Swarts S, Kruger HS, Dolman RC. Factors affecting mothers' choice of breastfeeding vs formula feeding in the lower Umfolozi district war memorial hospital, KwaZulu-Natal. Health SA Gesondheid. 2010;15(1):119-126.

27. Bhutta ZA, Das JK, Rizvi A, et al. Evidence-based interventions for improvement of maternal and child nutrition: what can be done and at what cost? Lancet. 2013:382(9890):452-477.

28. Zulliger R, Abrams EJ, Myer L. Diversity of influences on infant feeding strategies in women living with HIV in Cape Town, South Africa: a mixed methods study. Trop Med Int Health. 2013;18(12):1547-1554.

29. Oladokun RE, Brown BJ, Osinusi K. Infant-feeding pattern of HIV-positive women in a prevention of mother-to-child transmission (PMTCT) programme. AIDS Care. 2010;22(9):1108-111

30. Obermeyer CM, Castle S. Back to nature? Historical and cross cultural perspectives on barriers to optimal breastfeeding. Med Anthropol J. 1996;17(1):39-63.

31. Webb-Girard A, Cherobon A, Mbugua S, et al. Food insecurity is associated with attitudes towards exclusive breastfeeding among women in urban Kenya. Matern Child Nutr. 2012;8(2):199-214.

32. Hurley KM, Black MM, Papas MA, Quigg AM. Variation in breastfeeding behaviours, perceptions, and experiences by race/ethnicity among a low-income state-wide sample of Special Supplemental Nutrition Program for Women, Infants, and Children (WIC) participants in the United States. Matern Child Nutr. 2008;4(2):95-105.

33. Hall J. Effective community-based interventions to improve exclusive breast feeding at four to six months in low-and low-middle-income countries: a systematic review of randomised controlled trials. Midwifery. 2011;27(4):497-502.

34. Kidney E, Winter HR, Khan KS, et al. Systematic review of effect of community-level interventions to reduce maternal mortality. BMC Pregnancy Childbirth. 2009;9:2.

35. Radwan H. Patterns and determinants of breastfeeding and complementary feeding practices of Emirati Mothers in the United Arab Emirates. BMC Public Health. 2013;13(171):1-11.

36. Du Plessis L. Infant and young child feeding in South Africa: Stop the crying, beloved country. S Afr J Clin Nutr. 2013;26(1):4-5.

37. Taylor M, Jinabhai C, Dlamini S, etal. Effects of a teenage pregnancy prevention programme in KwaZulu-Natal, South Africa. Health Care Women Int. 2014;35(7-9):845-858.

38. Esterik PV. Contemporary trends in infant feeding research. Ann Rev Anthropol. 2002;31:257-278.

39. Birch LL, Fisher J0. Development of eating behaviours among children and adolescents. Paediatrics. 1998;101(3 Pt 2):539-549.

40. Buskens I, Jaffe A, Mkhatshwa $\mathrm{H}$. Infant feeding practices: realities and mindsets of mothers in southern Africa. AIDS Care. 2007;19(9):1101-1109.

41. Burns PJ. HIV, breastfeeding and infant mortality: weighing the impact of the nonevidenced-based WHO/UNAIDS recommendations in the low-income, low-resource countries. Boston: Boston University, 2001.

42. Edmond KM, Kirkwood BR, Amenga-Etego S, et al. Effect of early infant feeding practices on infection-specific neonatal mortality: an investigation of the causal links with observational data from rural Ghana. Am J Clin Nutr. 2007;86(4):1126-1131.

43. Duijts L, Jaddoe VW, Hoffman A, Moll HA. Prolonged and exclusive breastfeeding reduces the risk of infectious diseases in infancy. Paediatrics. 2010;126(1):e18-e25.

44. Kramer M, Kakuma R. Optimal duration of exclusive breastfeeding. [Cochrane review]. In: The Cochrane Library, Issue 8, 2012. Oxford: Update Software.

45. Schmied V, Beake S, Sheehan A, et al. Women's perceptions and experiences of breastfeeding support: a meta-synthesis. Birth. 2011;38(1):49-60. 